\title{
Monophasic action potential of the right atrium in paroxysmal atrial flutter and fibrillation
}

\author{
S. Gavrilescu, S. Cotoi, and T. Pop \\ From the First Medical Clinic, Institute of Medicine, Timişoara, Rumania
}

In 7 patients with paroxysmal atrial flutter, the monophasic action potential of the right atrium was recorded, using a suction electrode catheter technique. In all, 34 arrhythmic episodes were recorded and analysed; each episode of arrhythmia being initiated by a premature beat. It was possible to record only one or two flutter waves following an atrial premature beat. The wide variation of the vulnerable period and critical modifications of the refractoriness of the atrial myocardium may explain the onset and the cessation of paroxysmal dysrhythmic episodes.

Experimental studies (Hoffman et al., 1959) have shown that monophasic action potentials recorded with a suction electrode from isolated perfused rabbit hearts have the same shape and duration as transmembrane action potentials obtained with intracellular microelectrodes. It was also suggested that the study of the monophasic action potential from intact human heart may provide additional information about the electrophysiological events during sinus rhythm and various arrhythmias (Olsson, 197I, 1972).

In a former study (Gavrilescu and Cotoi, 1972) it was found that monophasic action potential recordings during the transition from atrial flutter to sinus rhythm, which followed DC shock, showed a progressive prolongation of the duration of flutter complexes. When a critical duration was reached sinus rhythm occurred spontaneously. These data were interpreted as the expression of the prolongation of the refractory period of the atrial muscle which may interrupt the re-entry mechanism.

The present paper describes the data observed in 7 patients with paroxysmal atrial flutter and fibrillation where 34 episodes of arrhythmia were recorded, where it was possible to study the onset as well as the spontaneous cessation of the arrhythmic episodes.

\section{Technique and subjects}

A bedside method, as previously described (Gavrilescu, Cotoi, and Pop, r972), using bipolar suction electrode catheters, allowed the recording of the monophasic action potential from the intact human heart.

Received 27 November 1972.
Seven patients, age 40 to 63 , were studied. All of them were complaining of recurrent attacks of arrhythmia associated with palpitations and sometimes with dizziness. Atrial flutter was diagnosed at the time of paroxysms on standard electrocardiograms. In 3 of the patients short bouts of atrial fibrillation were also noted. The history of these arrhythmic episodes ranged from 2 to 4 years. None of the patients had severe underlying heart disease or signs of congestive heart failure, but there was a hyperthyroid state in 3 patients. The paroxysms of flutter were often associated with nervous or physical strain.

In order to have additional information about the nature of arrhythmia, monophasic action potential recordings were performed. No antiarrhythmic drugs were given 3 days before, and no premedication, all the patients being in sinus rhythm. During the recording short bouts of atrial flutter occurred in our patients, lasting from a few seconds to four minutes. In Cases 2 and 6, besides atrial flutter, episodes of atrial fibrillation were also recorded. In Case 4, carotid sinus massage induced short periods of atrial flutter and, on two occasions, atrial fibrillation. In all but one case, sinus rhythm was resumed spontaneously. In Case 7 paroxysms of atrial flutter were recorded repeatedly and a stable sinus rhythm was obtained only after intravenous injection of $0.2 \mathrm{mg}$ acetyldigitoxin. In all the cases studied the suction was maintained for about 5 minutes and then repeated, in order to record several transitions from sinus rhythm to flutter and vice versa.

Right atrial monophasic action potential duration was measured on the baseline, and the vulnerable period was estimated. The coupling index (Killip and Gault, 1965) was also established for each arrhythmic episode.

$$
\text { (Coupling index }=\frac{\text { Coupling interval }}{\text { Preceding cycle length }}=\frac{\mathbf{P}_{2}-\mathbf{P}^{\prime}}{\mathbf{P}_{1}-\mathbf{P}_{2}} \text { ) }
$$




\section{Results}

Thirty-four episodes of paroxysmal atrial flutter and fibrillation were observed and recorded. In each case the onset of the arrhythmic episode was initiated by an atrial premature beat. The vulnerable period and the coupling index of the initiating premature beat showed considerable variation from case to case, but remained within close limits for the same patient (Table). In Case 4, in which atrial flutter and fibrillation were induced by carotid sinus pressure, the coupling index was very short, due to bradycardia induced by the procedure.

The principal data obtained in our patients, including the right atrial monophasic action potential recordings, are shown in the Table.
Fig. I and 2 illustrate the starting mechanism of atrial flutter in Case I. An atrial premature beat falling in the vulnerable period of the atrium may be followed by a short run of flutter waves (Fig. I) or by only one or two such waves as in Fig. 2.

In Case 4, short attacks of atrial fibrillation could be induced during carotid sinus stimulation (Fig. 3).

It is interesting to note that the first flutter beat which follows the initiating atrial premature beat has a monophasic action potential duration between 160 and $230 \mathrm{msec}$, while the duration of monophasic action potential of flutter waves during the arrhythmia ranged between 135 and $190 \mathrm{msec}$. The relation between the duration of right atrial monophasic action potential during atrial flutter and the pre-

TABLE Principal data in 7 patients with paroxysmal atrial flutter and fibrillation

\begin{tabular}{|c|c|c|c|c|c|c|c|c|c|c|c|c|c|}
\hline \multirow{3}{*}{$\begin{array}{l}\text { Case } \\
\text { No. }\end{array}$} & \multirow[t]{3}{*}{$\operatorname{Sex}$} & \multirow{3}{*}{$\begin{array}{l}\text { Age } \\
(y r)\end{array}$} & \multicolumn{2}{|c|}{ Sinus rhythm } & \multicolumn{5}{|c|}{ Atrial flutter } & \multirow{2}{*}{\multicolumn{2}{|c|}{$\begin{array}{l}\text { Initiating pre- } \\
\text { mature beat }\end{array}$}} & \multirow{3}{*}{$\begin{array}{l}\text { No. of } \\
\text { arrhyth- } \\
\text { mias }\end{array}$} & \multirow[t]{3}{*}{ Observations } \\
\hline & & & \multirow[t]{2}{*}{ Rate } & \multirow{2}{*}{$\begin{array}{l}M A P \\
\text { dura- } \\
\text { tion } \\
\text { (msec) }\end{array}$} & \multirow{2}{*}{$\begin{array}{l}\text { Atrial } \\
\text { rate }\end{array}$} & \multirow{2}{*}{$\begin{array}{l}\text { Ven- } \\
\text { tricular } \\
\text { rate }\end{array}$} & \multicolumn{3}{|c|}{$M A P$ duration (msec) } & & & & \\
\hline & & & & & & & $\begin{array}{l}\text { First } \\
\text { wave }\end{array}$ & $\begin{array}{l}\text { During } \\
\text { flutter }\end{array}$ & $\begin{array}{l}\text { Last } \\
\text { wave }\end{array}$ & $\begin{array}{l}\text { PP } \\
\text { interval } \\
\text { (vulner- } \\
\text { ability) } \\
\text { (msec) }\end{array}$ & $\begin{array}{l}\text { Coupling } \\
\text { index }\end{array}$ & & \\
\hline I & $M$ & 40 & 94 & 270 & 280 & 120 & I90 & 160 & 190 & $470-480$ & $0.68-0.80$ & 6 & Hyperthyroidism \\
\hline 2 & $\mathbf{M}$ & 63 & 84 & 230 & 350 & I 40 & I60 & I35 & 190 & $290-300$ & $0.45-0.47$ & 7 & $\begin{array}{l}\text { Hyperthyroidism, } \\
\text { atrial fibrillation }\end{array}$ \\
\hline 3 & $\mathrm{~F}$ & 63 & 70 & 320 & 280 & 150 & 200 & 150 & I90 & $440-450$ & $0.63-0.70$ & 2 & - \\
\hline 4 & $M$ & 43 & 80 & 350 & 240 & 100 & 200 & 155 & 200 & $400-410$ & $0.16-0.24$ & 3 & $\begin{array}{l}\text { Carotid sinus } \\
\text { massage, atrial } \\
\text { fibrillation }\end{array}$ \\
\hline 5 & $\mathbf{M}$ & 54 & 90 & 280 & 290 & 120 & 190 & 165 & 210 & $280-290$ & $0.32-0.50$ & 4 & Hyperthyroidism \\
\hline 6 & $M$ & 56 & 82 & 250 & 270 & 100 & 200 & 160 & 200 & $290-310$ & $0.20-0.34$ & 2 & Atrial fibrillation \\
\hline 7 & $M$ & 57 & 60 & 360 & 240 & 120 & 230 & I90 & 220 & $420-440$ & $0.25-0.26$ & Io & - \\
\hline
\end{tabular}

MAP $=$ Monophasic action potential

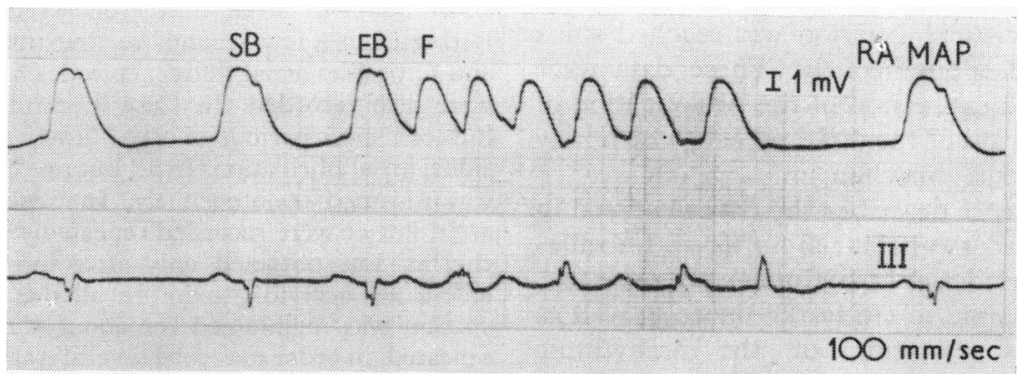

FIG. I The upper curve is the right atrial monophasic action potential (RAMAP), the bottom one is lead III of the standard electrocardiogram, recorded in Case I (Table). A short bout of atrial flutter $(F)$ is initiated by an atrial premature beat $(E B)$. The progressive prolongation of the monophasic action potential duration of the flutter waves which precedes the termination of the dysrhythmic episode can be noted. MAP duration: sinus beat $(S B): 270 \mathrm{msec}$; atrial premature beat (EB): $240 \mathrm{msec}$; last flutter wave: $200 \mathrm{msec}$. Paper speed 100 $\mathrm{mm} / \mathrm{sec}$. 


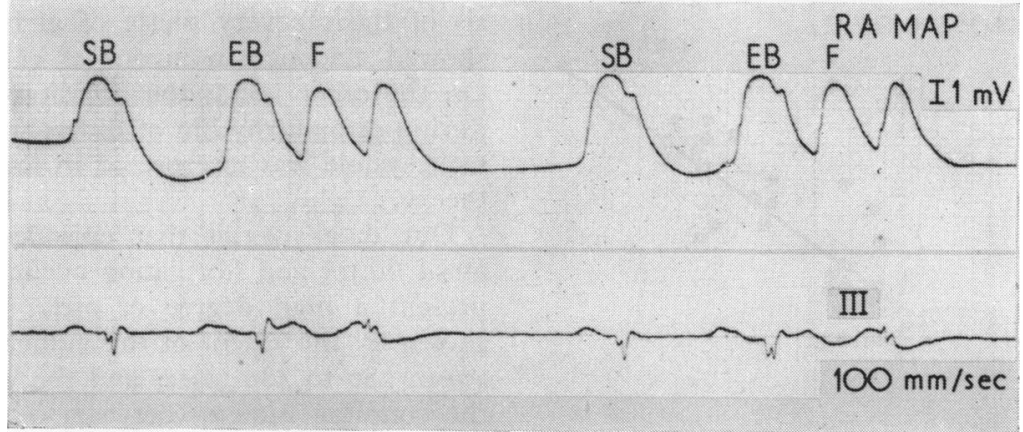

FIG. 2 The upper curve shows the RAMAP, the bottom curve lead III of the standard electrocardiogram in the same patient as Fig. $I$. The second and the sixth complexes are atrial premature beats $(E B)$, followed by two flutter waves $(F)$. The duration of MAP of the flutter waves is 190 msec. Paper speed $100 \mathrm{~mm} / \mathrm{sec}$.

ceding cycle length is illustrated in Fig. 4. Twentyfour patients with permanent or paroxysmal atrial flutter are included in the regression analysis.

It was seen that the spontaneous cessation of the flutter episodes was constantly associated with the prolongation of the right atrial monophasic action potential duration of the flutter waves between 190 and $200 \mathrm{msec}$. The termination and the onset of atrial flutter are illustrated in Fig. 5, in which a short strip of sinus rhythm between two attacks of atrial flutter is shown.

In one patient (Case 7) we have observed that after the end of the episode of flutter, one isolated atrial premature beat again initiated the arrhythmia, without any sinus activity (Fig. 6).

\section{Discussion}

The onset, course, and termination of arrhythmic episodes can be analysed on monophasic action potential recordings, which allow an overamplification of the electrical atrial activity. In a predominantly surface electrocardiographic study of patients in whom atrial fibrillation was converted to sinus rhythm by DC shock, Killip and Gault (1965) showed that relapse into atrial fibrillation was always

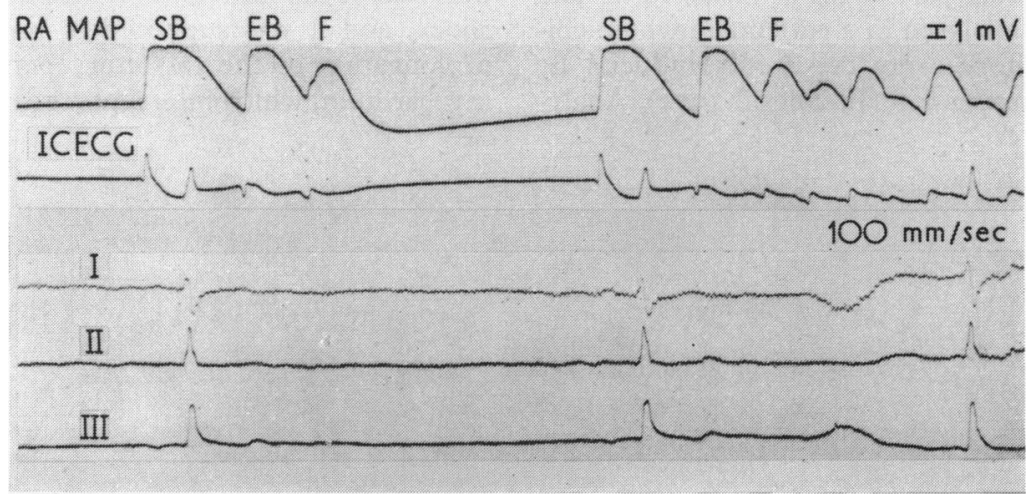

FIG. 3 Simultaneous recordings of RAMAP, intracavitary electrocardiogram (ICECG) and leads I, II, and III of the standard cardiogram, in Case 4 (Table) during carotid sinus massage. The first group of three complexes are: a sinusbeat (SB) (MAP duration: $350 \mathrm{msec}$ ); an atrial premature beat $(E B)$ (MAP duration: $270 \mathrm{msec}$ ); and a third complex which has the characteristics of a flutter wave $(F)$ (MAP duration $200 \mathrm{msec}$ ). The next sinus beat is followed again by an atrial premature beat, a flutter wave, and then continues with a disorganized atrial activity showing the pattern of atrial fibrillation. 


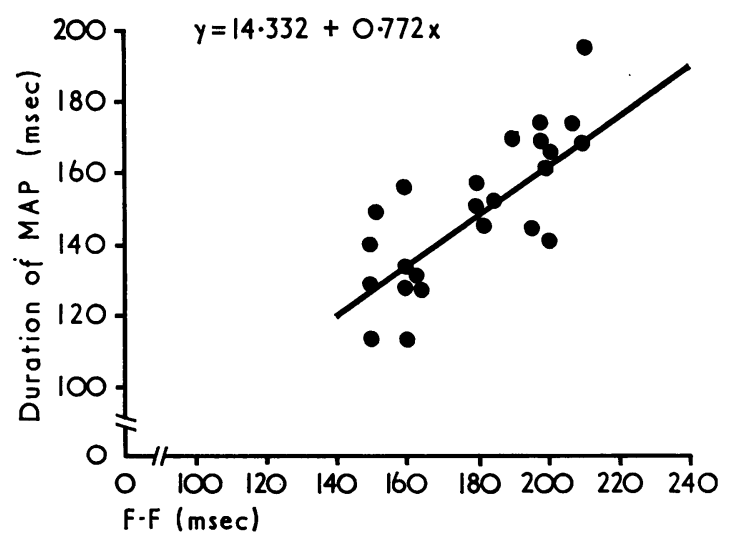

FIG. 4 Duration of right atrial MAP during atrial flutter in relation to preceding cycle length in 24 patients with permanent and paroxysmal atrial flutter $(r=0.912$, and $P<0.001)$.

preceded by an atrial premature beat with a short coupling index of about 0.48 per cent. In patients with acute myocardial infarction in whom an intracavitary electrocardiogram was monitored, it was found (Bennett and Pentecost, 1970) that atrial fibrillation was initiated by an atrial premature beat followed by atrial tachycardia of about 340 a minute, then the ectopic rhythm changed into the fibrillation pattern. It was assumed that the change of atrial wave shape which precedes the spontaneous cessation of atrial fibrillation was due to the slowing of the ectopic focal discharge. The onset, course, and termination of short paroxysms of atrial flutter and fibrillation were analysed in 2 patients in whom episodes of arrhythmia were repeatedly induced by carotid sinus compression (El-Sherif, 1972). Analy- sis of the recovery phase of arrhythmic episodes showed evidence in favour of re-entrant activity. On the other hand, the occasional demonstration during ectopic rhythm of different types of regular tachysystole was interpreted in favour of the focal theory.

Our data suggest that episodes of paroxysmal atrial flutter and fibrillation occur in patients who present a high degree of atrial vulnerability, as shown by the extent of the vulnerable period (between 280 to $480 \mathrm{msec}$ ) and the wide variation of the coupling indices (between 0.20 to 0.80 ). The shortest coupling indices $(0.20$ to 0.45$)$ were followed by atrial fibrillation and occurred during carotid sinus stimulation which shortens the atrial refractory period (Abildskov, Millar, and Burgess, 1971).

The limit of the atrial vulnerable period found in our patients was between 280 and $480 \mathrm{msec}$, compared with 180 to $280 \mathrm{msec}$ found by Haft et al. (1968) in 3 normal subjects in whom episodes of atrial fibrillaion were induced during atrial pacing.

Experimental studies (Antoni, 1972) have shown that the duration of the action potential of a premature beat is shorter when it appears earlier after the preceding sinus beat. The short duration of the action potential which expresses a short refractory period, allows the re-entry, and the succession of atrial monophasic action potential complexes, as shown in Fig. 2 and 3.

The spontaneous termination of the flutter episodes also deserves a few comments. A progressive prolongation of the monophasic action potential duration of the flutter waves was observed after DC shock, and it was supposed to represent a critical prolongation of the refractory period of the atrial myocardium, which interrupts the re-entry mechan-

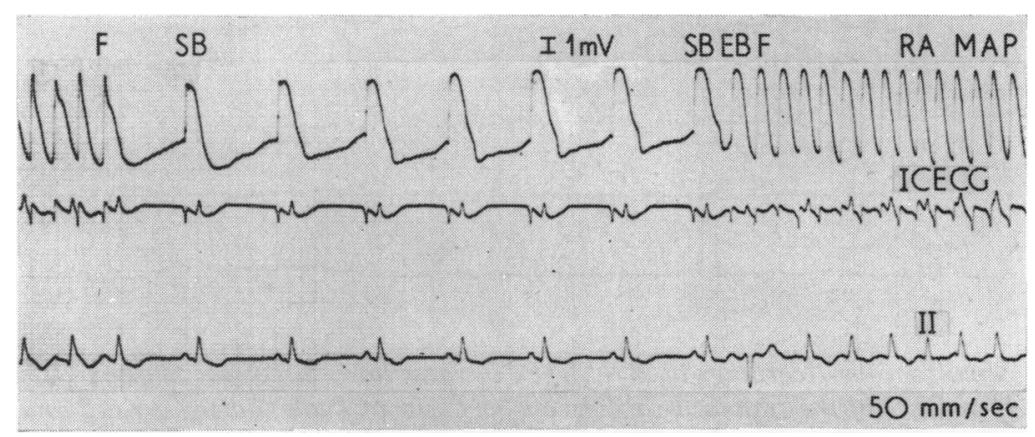

FIG. 5 Simultaneous recording of the RAMAP, ICECG, and lead II, in Case 2 (Table), showing a strip of sinus rhythm $(S B)$ preceded and followed by atrial flutter $(F)$. MAP duration: sinus beat: $230 \mathrm{msec}$; flutter wave: $160 \mathrm{msec}$; last flutter wave: $190 \mathrm{msec}$. EB: premature beat. Paper speed $50 \mathrm{~mm} / \mathrm{sec}$. 


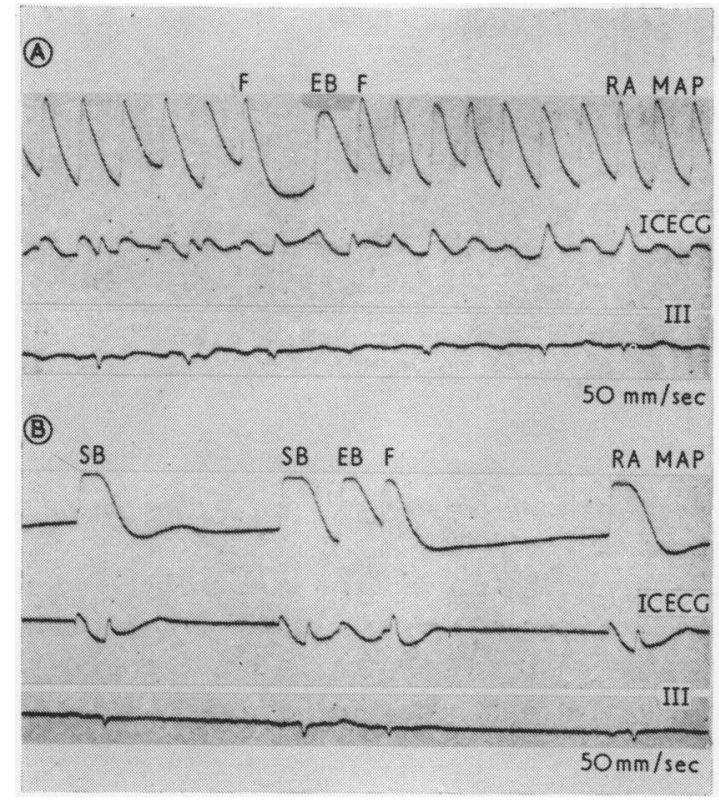

FIG. 6 Simultaneous recording of RAMAP, ICE$C G$, and lead II in Case 7 (Table). Paper speed $50 \mathrm{~mm} / \mathrm{sec}$. $(A)$ An episode of atrial flutter $(F)$, interrupted by one atrial premature beat $(E B)$ initiating the relapse of the arrhythmia. (B) In the same patient, a sinus beat $(S B)$, followed by an atrial premature beat $(E B)$ and one flutter wave $(F)$. The identity between the two extrasystoles $(E B)$ can be noted.

ism (Gavrilescu and Cotoi, 1972). We do not know whether the flutter stops because the atrial rate decreases or because the refractoriness of the atrial muscle is increased, but we consider the latter explanation to be more plausible.

The short right atrial monophasic action potential duration, during sinus rhythm, found in Cases I, 2 , and 5 may be correlated with a hyperthyroid state, a condition in which such arrhythmias are common (Cotoi, Constantinescu, and Gavrilescu, 1972).

The data mentioned above suggest that critical modifications of the refractoriness of the atrial muscle can have an important role in the onset and cessation of paroxysmal atrial flutter and fibrillation. The high degree of atrial vulnerability and the facilitating role of the re-entry by a short refractory period may explain the paroxysmal character of dysrhythmia. The observation of one case in which the atrial flutter is interrupted by one premature atrial beat and relapses without any sinus beat (Fig. 6) is in agreement with the concept of the high atrial vulnerability.

\section{References}

Abildskov, J. A., Millar, K., and Burgess, M. J. (197I). Atrial fibrillation. American fournal of Cardiology, 28, 263.

Antoni, H. (1972). Physiologische Grundlagen bei der Erzeugung und Unterbrechung von Vorhof- und Kammerflimmern des Herzens durch den elektrischen Strom. Herz/Kreislauf, 4, 324.

Bennett, M. A., and Pentecost, B. L. (1970). The pattern of onset and spontaneous cessation of atrial fibrillation in man. Circulation, 41, 981.

Cotoi, S., Constantinescu, L., and Gavrilescu, S. (1972). The effect of thyroid state on monophasic action potential in human heart. Experientia, 29, 797.

El-Sherif, N. (1972). Paroxysmal atrial flutter and fibrillation. Induction by carotid sinus compression and prevention by atropine. British Heart fournal, 34, 1024.

Gavrilescu, S., and Cotoi, S. (1972). Monophasic action potential of right human atrium during atrial flutter and after conversion to sinus rhythm. Argument for re-entry theory. British Heart fournal, 34, 396.

Gavrilescu, S., Cotoi, S., and Pop, T. (1972). The monophasic action potential of the right atrium. Cardiology, 57, 200.

Haft, J. I., Lau, S. H., Stein, E., Kosowsky, B. D., and Damato, A. N. (1968). Atrial fibrillation produced by atrial stimulation. Circulation, 37, 70.

Hoffman, B. F., Cranefield, P. F., Lepeschkin, E., Surawicz, B., and Herrlich, H. C. (I959). Comparison of cardiac monophasic action potentials recorded by intracellular and suction electrodes. American fournal of Physiology, 196, 1297.

Killip, T., and Gault, J. H. (1965). Mode of onset of atrial fibrillation in man. American Heart fournal, 70, 172.

Olsson, S. B. (197I). Monophasic Action Potentials of Right Heart. Elanders Boktryckeri Akienbolag, Göteborg.

Olsson, S. B. (1972). Recording of monophasic action potentials in the study of atrial dysrhythmias. Giornale Italiano di Cardiologia, 2, I4I.

Requests for reprints to Professor S. Gavrilescu, I-st Medical Clinic, Str. Gh. Dima 5, Timişoara, Rumania. 